\title{
Knowledge and practices of general surgeons and residents regarding spilled gallstones lost during laparoscopic cholecystectomy: a cross sectional survey
}

Muhammad Sohaib Khan ${ }^{1 *}$, Muhammad Adil Khatri ${ }^{1}$, Muhammad Shoaib Khan ${ }^{1}$ and Zakiuddin G Oonwala ${ }^{2}$

\begin{abstract}
Background: Gall bladder perforation, gallstone spillage and loss are commonly reported from Laparoscopic Cholecystectomy (LC). Though rare, lost gallstones can cause a variety of complications presenting variably from within 1 month to 20 years postoperatively. Our objective was to investigate knowledge and practices of surgeons and surgical residents regarding spilled gallstones lost during laparoscopic cholecystectomy.

Methods: An observational, cross-sectional survey, using a questionnaire based on 13 self-answered close-ended questions, was conducted at 6 different post-graduate centers in Karachi, Pakistan.

Results: Of the 82 participants, 23 (28\%) were consultant surgeons while 59 (72\%) were general surgery residents. $86 \%$ of participants were aware that stones lost during LC can cause complications. Out of the 18 reported complications presented, only $20 \%$ participants identified more than 8 complications for which they can consider lost gallstones causal. 28\% of participants weren't aware about the expected postoperative duration for presentation of complications. Only 15\% of our participants expected complications beyond 5 years of the procedure. $72 \%$ of participants will not convert to open cholecystectomy to retrieve lost gallstones. While $88 \%$ of participants agreed that lost gallstones should be documented in operative notes, only $70 \%$ reported that it's actually done in practice. 55\% of participants agreed to have possibility of lost gallstones as part of the informed consent but in practice it's included according to only $31 \%$ of participants. $68 \%$ of participants believe that patients should be informed if gallstones are lost but in actual practice only $41 \%$ participants inform patients when gallstones are lost during procedure.

Conclusions: We conclude that there is a dearth of awareness regarding diversity of complications from lost gallstones and about their variable postoperative duration of presentation. The practices involving lost gallstones management, documentation and patient information were found to vary widely. Proper awareness is imperative as it may compel surgeons to undertake all possible measures to retrieve spilled gallstones and progress towards better and standardized practices in managing lost gallstones.
\end{abstract}

\footnotetext{
* Correspondence: m.sohaib.khan@hotmail.com

'Civil Hospital, Baba-e-urdu Road, Karachi, Pakistan

Full list of author information is available at the end of the article
} 


\section{Introduction}

Laparoscopic cholecystectomy (LC) is a commonly performed procedure in general surgical units all over the world. The inherent advantages of the procedure that include low postoperative morbidity with a significant economic impact were recognized after few years of its introduction. In 1992, the consensus statement from the National Institute of Health (NIH) Conference accepted LC as the treatment of choice for patients with symptomatic gallstones [1].

Like any other procedure, LC has known complications of which iatrogenic perforation and gallstone spillage are more commonly reported. The incidence of gall bladder perforation during LC has been reported to be up to $36 \%$ [2] with reported spillage of gallstones as high as 16\% [3]. Though rare, the gallstones spilled during LC if left unretrieved can result in serious complications [4]. A review of the Medline database for reports on lost gallstones during LC found septic, fistulous and even intestinal complications with variable presentations in a wide variety of locations [5]. These complications have been reported to present within a month to up to 20 years after the procedure $[3,6]$.

There is a lack of consensus on the management of spilled gallstones lost during LC. For some surgeons the rarity of complications dismisses the prospects of converting the $\mathrm{LC}$ to an open procedure for retrieving the spilled stones, while for others the seriousness of complications demands that every effort be made to retrieve all gallstones spilled during the procedure. Mullerat [7] reported that only a fifth of surgeons include this phenomenon in the informed consent and only half the surgeons inform the patients in case the stones are lost during LC. They observed that informing the patients may aid in the diagnosis of the complications if in case they occur, but can also result in unnecessary anxiety and repeated examinations for rare complications.

It is clear that awareness of the possible complications of this condition amongst the surgical team is necessary for making an informed decision about its timely management. Our objective was to investigate the knowledge and practices of surgeons and surgical residents regarding spilled gallstones lost during LC in post graduate training centers of Karachi, Pakistan.

\section{Methodology}

This was an observational, cross-sectional survey with participants belonging to 6 different post-graduate centers in Karachi, Pakistan. The centers included Dow University of Health Sciences, Hamdard University Hospital, the Aga Khan University Hospital, Abbasi Shaheed Hospital, Liaquat National Postgraduate Medical Center and the Indus Hospital.
The participants included practicing surgeons and surgeons at different levels of training and a convenient sample was obtained.

\section{The questionnaire}

The survey consisted of 13 self-answered close-ended questions. The questionnaire covered 5 aspects of spilled gallstones lost during laparoscopic cholecystectomy including: 1) knowledge of occurrences, 2) knowledge of complications, 3) management, 4) documentation and 5) patient information. The questionnaire was divided into 2 parts to assess attitudes and practices of the participants. The questionnaire was validated and standardized by conducting a pilot study on 10 participants.

\section{Results}

Of the 82 participants, 23 (28\%) were consultant surgeons while $59(72 \%)$ were residents of general surgery at different post-graduate training levels. Overall, 47 (57\%) participants were from public-sector hospitals and 35 (43\%) from private-sector teaching hospitals.

\section{Knowledge}

Majority (86.5\%) of the participants had experience with lost gallstones during LC. Responding to the question of prevalence of lost gallstones in LC, $60 \%$ participants held it was less than $5 \%$. In response to the question regarding vulnerability of technique, $43 \%$ considered both single and multiple port to be equally vulnerable while $24 \%$ considered single port to be more vulnerable. Up to $83 \%$ of respondents were aware of the possibility of complications from lost gallstones as opposed to $10 \%$ of our participants who believed that lost stones cannot cause complications. Out of the 18 reported complications presented (Table 1), participants were to identify complications that they can consider causal from lost gallstones (Figure 1). 20\% of the participants identified more than 8 complications, $60 \%$ of participants identified less than 9 complications while $20 \%$ of participants did not identify any complication. When asked about the duration

Table 1 List of reported complications presented to survey participants with references

\begin{tabular}{ll}
\hline Sinus formation [8] & Bladder obstruction [9] \\
\hline Dyspareunia [10] & Empyema [11] \\
\hline Colocutaneous fistula [12] & Subhepatic abscess [13] \\
\hline Cholelithoptysis [14] & Liver abscess [15] \\
\hline Pelvic abscess [16] & Hematuria [17] \\
\hline Septicimia [18] & Intra-abdominal abscess [19] \\
\hline Retroperitoneal abscess [20] & Intestinal Obstruction [21] \\
\hline Granuloma formation [22] & Loin abscess [23] \\
\hline Incarcerated hernia [24] & Port site infection [25] \\
\hline
\end{tabular}




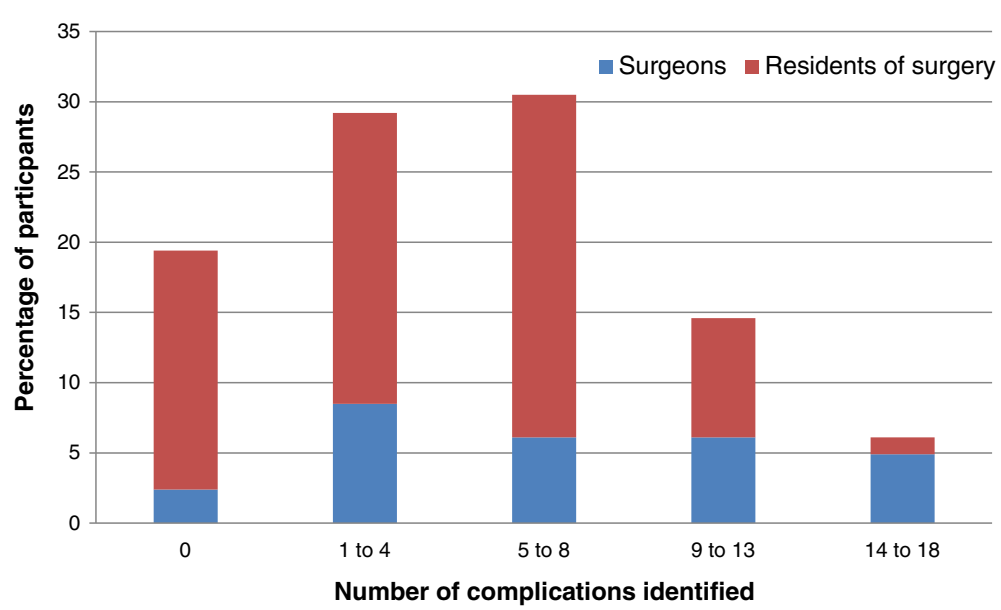

Figure 1 Presented complications from lost gallstones as in Table 1 identified as causal.

post LC at which complications can present (Figure 2), $28 \%$ of participants were not aware about the expected duration. $30 \%$ of participants expect complications for a year after the procedure while $17 \%$ expect complications for 5 years. Only 15\% expect complication beyond five years of the procedure.

\section{Attitude and practice}

In case spilled stones are lost, $72 \%$ of survey participants will not convert LC to open cholecystectomy, though $18 \%$ of the participants will convert to open in case gallstones are lost while $7 \%$ of participants did not know. Documentation of lost gallstones in operative notes should be done according to $88 \%$ of participants but only $70 \%$ of participants said that it is actually documented while according to $9 \%$ of participants, documentation of lost gallstones is done 'sometimes'. According to $16 \%$ of participants lost gallstones are never documented.

Regarding aspects of patient counseling, 55\% participants responded that the patient should be informed prior to surgery as part of the informed consent regarding possibility of lost gallstones. However, $47 \%$ participants reported that patients are never informed prior to surgery in actual practice, while $31 \%$ believed that patients are informed. Postoperatively, 68\% participants believe that patients should be informed if gallstones are lost. When asked about current practice, $41 \%$ participants informed patients of lost gallstones postoperatively, while $27 \%$ participants don't inform patients. According to $24 \%$ of participants, patients are informed 'sometimes' (Figure 3).

\section{Discussion}

Laparoscopic Cholecystectomy (LC), since its recognition as the treatment of choice for symptomatic cholelithiasis, has become one of the most commonly performed general surgical procedures. The laparoscopic technique, due to lower incidence of postoperative morbidity and early recovery, has become the gold standard for performing cholecystectomies [1]. Like all other

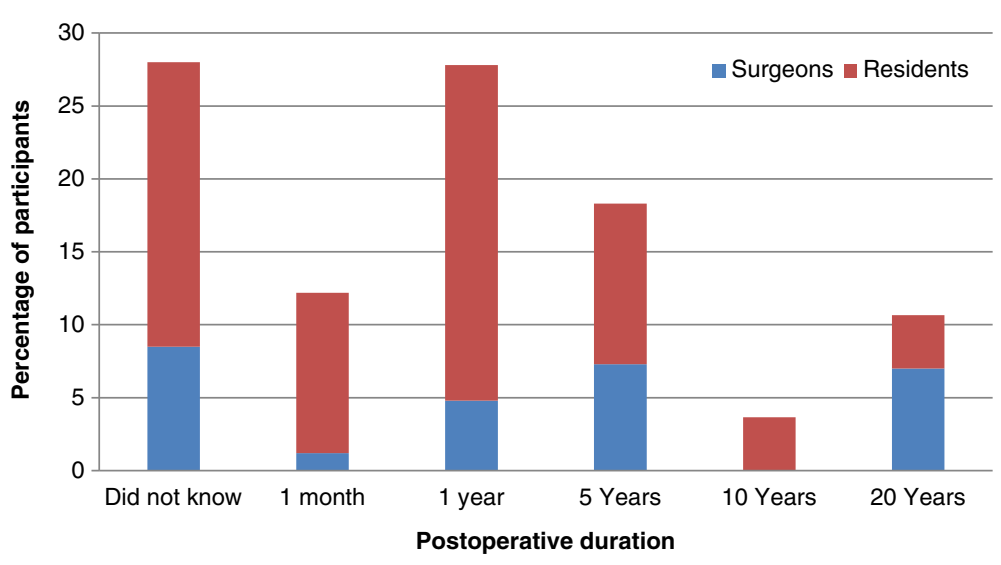

Figure 2 Expected postoperative duration for presentation of complications. 


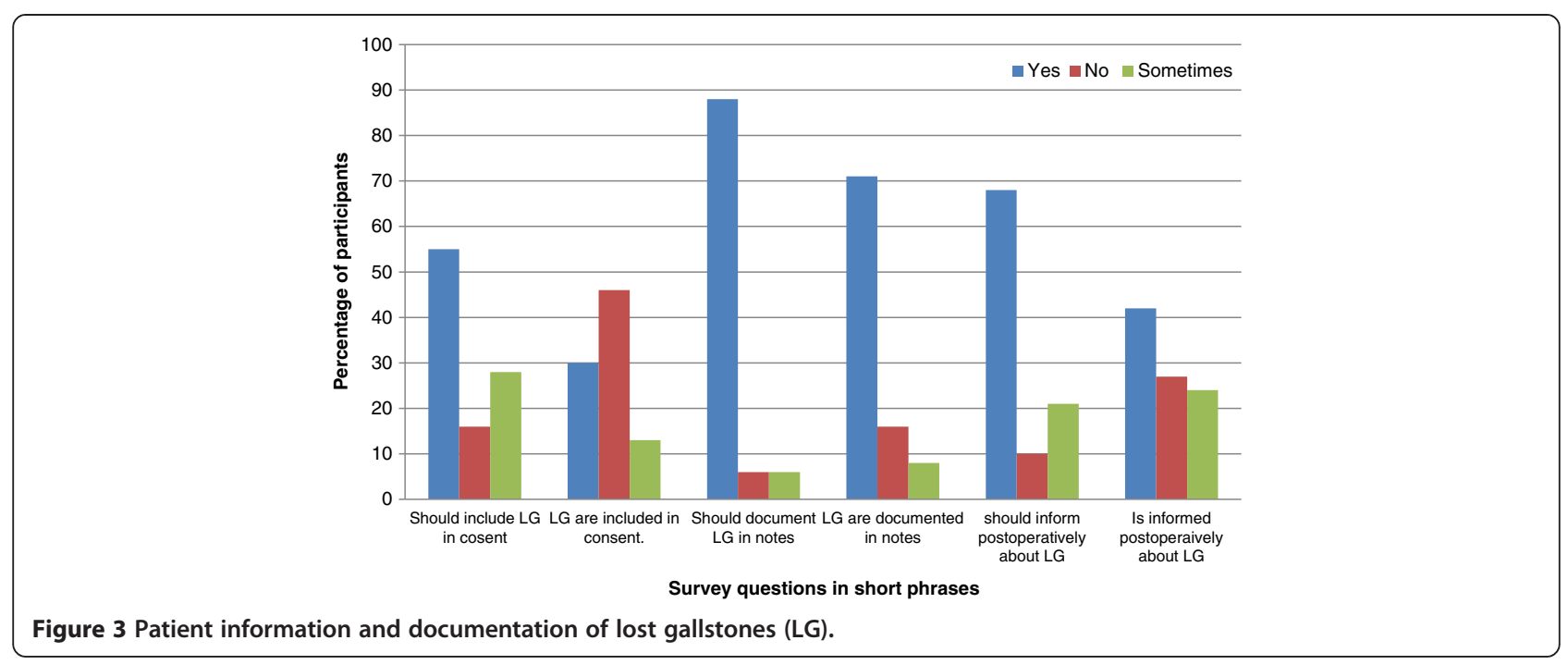

surgical interventions, LC has its known complications, of which bile duct injury is the most serious and dreaded complication. Fortunately the rate of this serious complication has been reported to be as low as $0.2 \%$ [26]. Gall bladder perforation and gall stone spillage are the other more common complications of LC. The incidence of gall bladder perforation during LC has been reported to be up to $36 \%$ [2] with reported spillage of gallstones as high as $16 \%$ [3]. Spilled gallstones are also lost during LC being reported to have occurred in $1.1 \%$ cases by Diez [27]. In our survey majority (86.5\%) of the participants agreed that gallstones are lost during LC. $60 \%$ of participants believed that stones are lost in up to $5 \%$ of LCs while according to $23 \%$ gallstones are lost in more than $5 \%$ of cases which is much greater than the percentage reported in the literature.

Spilled gallstones that are lost during LC rarely cause complications yet up to $83 \%$ of respondents of our survey were aware of the possibility of complications from lost gallstones as opposed to $10 \%$ who believed that lost stones cannot cause complications. A wide variety of complications presenting over a variable period post LC, have been reported in the literature. Abscesses are most frequently reported. These include intra-abdominal abscess [19], retroperitoneal abscess [20], pelvic abscess [16], loin abscess [23], subhepatic abscess [13] and liver abscess [15]. The diverse locations of these abscesses attest to the migratory nature of lost gallstones. This may also be the reason for many other varied complications that have been reported including colocutaneous fistula [12], intestinal obstruction [21], bladder obstructions [9], empyema [11], cholelithoptysis [20], septicemia [18], incarcerated hernia [24] and dyspareunia [10]. Out of the 18 reported complications from lost gallstones that were presented to the participants of our survey (Table 1), only $20 \%$ of the participants identified more than 8 complications for which they can consider lost gallstones causal. This shows that even though most of the participants of our survey aware about the possibility of complications from lost gallstones, a vast majority isn't aware about the variable nature of these complications.

Complications from lost gallstones present at variable durations postoperatively ranging from with a month to as much as 20 years post operatively $[3,6]$. In our survey, $28 \%$ of participants were not aware about the expected duration elaborating the dearth of awareness regarding this aspect. The expectations of only $15 \%$ of our participants were in accordance with the reported variability of postoperative duration of presentation as they expected complications even beyond 5 years of the procedure.

The rarity of complications from lost gallstones has raised the question that should patients be informed prior to surgery about the possibility of such an event. In a survey conducted by Mullerat [7], 80\% of surgeons don't have possibility of lost gallstones as part of informed consent. In our survey 55\% participants agreed that the patient should be informed prior to surgery regarding possibility of lost gallstones as part of the informed consent. However, $47 \%$ participants reported that patients are never informed prior to surgery in actual practice. In Pakistani medical practice, this split opinion also conforms to the already reported uncertainty of our medical practitioners regarding the amount information deemed appropriate for the patient with illiteracy of the patient being the major influence [28]. Prior to elective surgeries, patients in Pakistan have been reported to have very high levels of anxiety with fear of complications being the major reason behind it [29]. Proper counseling with clear understanding of incidences of various complications by the surgical team is essential as it will be instrumental in enhancing the patients' confidence ameliorating their anxiety. 
Moreover, conversion to open cholecystectomy for retrieval is not indicated as the benefits of the laparoscopic technique outweigh the threat posed by lost gallstones as they are very rare being reported in $0.08 \%$ to $0.58 \%$ cases of lost gallstones $[3,30]$. Yet the serious nature of these complications demands that every effort be made to retrieve spilled gallstones. $72 \%$ of our survey participants will not convert LC to open cholecystectomy. This indicates the unclear state of $28 \%$ our participants regarding the intra operative management of lost gallstones.

In the event that lost gallstones are lost, informing the patient presents as a predicament to the surgeon as on one hand it is necessary so that it may facilitate diagnosis of any future complications but such information may result in unnecessary anxiety to the patient. Postoperatively, $68 \%$ participants of our survey believe that patients should be informed if gallstones are lost. When asked about current practice, $41 \%$ participants informed patients of a lost gallstone postoperatively, while $27 \%$ respondents never informed patients. According to $24 \%$ of participants, patients are informed 'sometimes'. This split opinion regarding informing patients about lost gallstones has also been reported by Mullerat [7] with only $50 \%$ of surgeons actually informing patients in their survey.

In all instances, lost gallstones should be documented in operative notes as it may not only facilitate diagnosis of the resultant complications but will also allow an objective assessment of the incidence of lost gallstones. In our survey, documentation of lost gallstones in operative notes should be done according to $88 \%$ of participants but only $70 \%$ of participants report that it is done in actual practice while according to $9 \%$ of participants, documentation of lost gallstones is done 'sometimes'. According to $16 \%$ of participants lost gallstones are never documented. Wauben [31] has identified the inadequacy of operative notes of laparoscopic cholecystectomy being representative of the procedure. Our survey too has established that even lost gallstones are often not documented in operative notes elaborating their inadequacy further. From this revelation we can also anticipate that estimating the frequency of lost gallstones from operative notes alone will be underreporting the actual number of cases leading to misinterpretation of the practices at large.

\section{Conclusion}

We conclude that there is a dearth of awareness regarding the diversity of complications from lost gallstones as well as about their variable postoperative duration of presentation. The practices involving lost gallstones management, documentation and patient information were found to vary widely. With the revelation from our survey that lost gallstones are often not documented in the operative notes, we can anticipate that any estimation of the frequency of lost gallstones from operative notes alone will be under reporting the actual cases potentially leading to misinterpretation of the practices at large.

Opinions and practices of our survey participants were found to be specially divided in aspects of pre-operative consent and postoperative information for the patient. We recommend further investigation to ascertain the reasons behind this split opinion as then steps may be taken to promote more standardized evidence based practices allowing the patient to be fully informed about all possible predicaments that may ever arise without provoking any unnecessary anxiety.

Proper awareness of the surgical team regarding lost gallstones is imperative as it may then compel surgeons to undertake all possible measures to retrieve spilled gallstones and progress towards better and standardized practices involving lost gallstones ensuring safer surgeries and allowing prompt recognition of complications if ever they arise.

\section{Competing interests}

The authors declare that they have no competing interests.

\section{Authors' contributions}

MS (corresponding author) conceived and designed the project, identified its significance through literature search, designed the questionnaire, conducted the survey, analyzed and interpreted the data and wrote the manuscript. MA contributed to the literature search, designing of questionnaire, conducted the survey and was involved in analysis and interpretation of the data. MSK assisted the designing of questionnaire, provided statistical expertise in analysis and interpretation of data and assisted in writing of manuscript. ZGO supervised the whole project providing expert opinion and guidance on designing the questionnaire, facilitated the survey, provided critical insight on interpretation of data and also supervised the writing of manuscript. All authors read and approved the final manuscript.

\section{Author details}

${ }^{1}$ Civil Hospital, Baba-e-urdu Road, Karachi, Pakistan. ${ }^{2}$ Hamdard University Hospital, M.A. Jinnah Road, Karachi, Pakistan.

Received: 24 June 2013 Accepted: 11 August 2013

Published: 14 August 2013

\section{References}

1. Gallstones and Laparoscopic Cholecystectomy. NIH Conse Statement 1992, 10:1-20. http://www.ncbi.nlm.nih.gov/pubmed/1301217.

2. Hui TT, Giurgiu DI, Margulies DR, Takagi S, lida A, Phillips EH: latrogenic gallbladder perforation during laparoscopic cholecystectomy: etiology and sequelae. Am Surg 1999, 65:944-948.

3. Memon MA, Deeik RK, Maffi TR, Fitzgibbons RJ Jr: The outcome of unretrieved gallstones in the peritoneal cavity during laparoscopic cholecystectomy. A prospective analysis. Surg EndosC 1999, 13:848-857.

4. Diez J, Arozamena C, Gutierrez L, Bracco J, Mon A, Sanchez Almeyra R, Secchi M: Lost stones during laparoscopic cholecystectomy. HPB Surg 1998, 11:105-108.

5. Zehetner J, Shamiyeh A, Wayand W: Lost gallstones in laparoscopic cholecystectomy: all possible complications. Am J Surg 2007, 193:73-78.

6. Röthlin MA, Schöb O, Schlumpf R, Largiadèr F: Stones spilled during cholecystectomy: a long-term liability for the patient. Surg Laparosc EndosC 1997, 7:432-434

7. Mullerat J, Cooper K, Box B, Soin B: The case for standardisation of the management of gallstones spilled and not retrieved at laparoscopic cholecystectomy. Ann R Coll Surg Engl 2008, 90:310-312.

8. Cacdac RG, Lakra YP: Abdominal wall sinus tract secondary to gallstones: a complication of laparoscopic cholecystectomy. J Laparoendosc Surg 1993, 3:509-511 
9. Castro MG, Alves AS, Oliveira CA, Vieira Júnior A, Vianna JL, Costa RF: Elimination of biliary stones through the urinary tract: a complication of the laparoscopic cholecystectomy. Rev Hosp Clin Fac Med Sao Paulo 1999, 54:209-212.

10. Chanson C, Nassiopoulos K, Petropoulos P: Complications of intraperitoneal gallstones. Schweiz Med Wochenschr 1997, 16(127):1323-1328.

11. Willekes CL, Widmann WD: Empyema from lost gallstones: a thoracic complication of laparoscopic cholecystectomy. J Laparoendosc Surg 1996, 6:123-126.

12. Bouasker I, Zoghlami A, El Ouaer MA, Khalfallah M, Samaali I, Dziri C: Parietal abscess revealing a lost gallstone 8 years after laparoscopic cholecystectomy. Tunis Med 2010, 88:277-279.

13. Van Brunt PH, Lanzafame RJ: Subhepatic inflammatory mass after laparoscopic cholecystectomy. A delayed complication of spilled gallstones. Arch Surg 1994, 129:882-883.

14. Hanna SJ, Barakat O, Watkin S: Cholelithoptysis: an unusual delayed complication of laparoscopic cholecystectomy. J Hepatobiliary Pancreat Surg 2004, 11:190-192.

15. Steerman PH, Steerman SN: Unretrieved Gallstones Presenting as a Streptococcus bovis Liver Abscess. JSLS 2000, 4:263-265.

16. Protopapas A, Milingos S, Diakomanolis E, Kioses E, Rodolakis A, Michalas S: Septic lithiasis of the pelvis. Surg Endosc 2003, 17:159.

17. Famulari C, Pirrone G, Macrì A, Crescenti F, Scuderi G, De Caridi G, Giuseppe $\mathrm{AL}$ : The vesical granuloma: rare and late complication of laparoscopic cholecystectomy. Surg Laparosc Endosc Percutan Tech 2001, 11:368-371.

18. Van Mierlo PJ, De Boer SY, Van Dissel JT, Arend SM: Recurrent staphylococcal bacteraemia and subhepatic abscess associated with gallstones spilled during laparoscopic cholecystectomy two years earlier. Neth J Med 2002, 60:177-180

19. van der Lugt JC, de Graaf PW, Dallinga RJ, Stassen LP: Abscess formation due to lost stones during laparoscopic cholecystectomy. Ned Tijdschr Geneeskd 2005, 149:2683-2686.

20. Dashkovsky I, Cozacov JC: Spillage of stones from the gallbladder during laparoscopic cholecystectomy and complication of a retroperitoneal abscess mimicking gluteal abscess in elderly patients. Surg Endosc 2002, 16:717.

21. Habib E, Elhadad A: Digestive complcations of gallstones lost during laparoscopic cholecystectomy. HPB (Oxford) 2003, 5:118-122.

22. Tham $\mathrm{CH}, \mathrm{Ng}$ BK: Gallstone granuloma: a rare complication of laparoscopic cholecystectomy. Singapore Med J 2001, 42:174-175.

23. Helme S, Samdani T, Sinha P: Complications of spilled gallstones following laparoscopic cholecystectomy: a case report and literature overview. J Med Case Rep 2009, 3:8626.

24. Bebawi M, Wassef S, Ramcharan A, Bapat K: Incarcerated indirect inguinal hernia: a complication of spilled gallstones. JSLS 2000, 4:267-269.

25. Narreddy SR, Guleria S, Agarwal S, Svr CM, Mandal S: Recurrent abscess at site of laparoscopic cholecystectomy port due to spilled gallstones. Indian I Gastroenterol 2001, 20:161.

26. Ahmad J, McElvanna K, McKie L, Taylor M, Diamond T: Biliary complications during a decade of increased cholecystectomy rate. Ulster Med J 2012, 81:79-82.

27. Diez J, Arozamena C, Gutierrez L, Bracco J, Mon A, Sanchez Almeyra R, Secchi M: Lost Stones During Laparoscopic Cholecystectomy. HPB Surg 1998, 11:105-109.

28. Jafarey AM, Farooqui A: Informed consent in the Pakistani milieu: the physician's perspective. J Med Ethics 2005, 31:93-96.

29. Jawaid M, Mushtaq A, Mukhtar S, Khan Z: Preoperative anxiety before elective surgery. Neurosci (Riyadh) 2007, 12:145-148.

30. Schäfer M, Suter C, Klaiber C, Wehrli H, Frei E, Krähenbühl L: Spilled gallstones after laparoscopic cholecystectomy. A relevant problem? A retrospective analysis of 10,174 laparoscopic cholecystectomies. Surg Endosc 1998, 12:305-309.

31. Wauben LS, Goossens RH, Lange JF: Evaluation of Operative Notes Concerning Laparoscopic Cholecystectomy: Are Standards Being Met? World J Surg 2010, 34:903-909.

doi:10.1186/1754-9493-7-27

Cite this article as: Khan et al.: Knowledge and practices of general surgeons and residents regarding spilled gallstones lost during laparoscopic cholecystectomy: a cross sectional survey. Patient Safety in Surgery 2013 7:27.

\section{Submit your next manuscript to BioMed Central and take full advantage of:}

- Convenient online submission

- Thorough peer review

- No space constraints or color figure charges

- Immediate publication on acceptance

- Inclusion in PubMed, CAS, Scopus and Google Scholar

- Research which is freely available for redistribution 